\title{
3-Deaza-Adenosine Inhibition of Stimulus-Response Coupling in Human Polymorphonuclear Leukocytes
}

\author{
Joseph C. Fantone, Ricardo E. Duque, Bruce H. Davis, and Sem H. Phan \\ Department of Pathology, University of Michigan Medical School, Ann Arbor, Michigan (J.C.F., S.H.P.); Department \\ of Pathology, University of Florida College of Medicine, Gainesville, Florida (R.E.D.); Department of Pathology, \\ Dartmouth Medical School, Hanover, New Hampshire (B.H.D.)
}

\begin{abstract}
In an effort to define better the functional role of S-adenosyl-methionine-mediated methylation reactions in modulating polymorphonuclear (PMN) functional responses to chemotactic stimuli, we inveatigated the effects of 3-deaza-adenosine (3-DZA), a known inhibltor of methylation reactions in phagocytic cells, on formyl methionyl-leucylphenylalanine (FMLP)-induced responees in human PMN leukocytes. Using the fluorescent cyanine dye 3,3'-dipropyithiocarbocyanine (dl-S-C $\left.{ }_{3}-(5)\right)$ as an optical probe of membrane potential we obeerved that 3-DZA at concentrations that inhibit FMLP-induced $\mathrm{O}_{2}^{-}$production does not significantly after FMLP-Induced changes in transmembrane potential. Additional studles showed an inhibitory effect of 3-DZA on FMLP-induced PMN pinocytosis and to a lesser degree on FMLP-induced degranulation. However, pretreatment of PMNs with 3-DZA did not alter FMLP-induced changes in Quin-2 fluorescence, an indicator of changes in intracellular calcium levels. These findings demonstrate a diseociation between chemotactic factor-induced cell membrane depolarization, changes in intracellular calcium, and specific neutrophil functional responses and suggest that chemotactic factor-induced changes in transmembrane potential and intracellular calcium are independent of chemotactic factor-induced methylation reactions. Furthermore, 3-DZA did not after phorbol myristate acetate induced $\mathrm{O}_{2}^{-}$production or filuid pinocytosis indicating a stimulus specificlty for the inhibitory effects of this agent on $\mathrm{O}_{2}^{-}$production.
\end{abstract}

Key words: neutrophil, superoxide, methylation, transmembrane potential

\section{INTRODUCTION}

Polymorphonuclear leukocytes stimulated with chemotactic factors undergo a complex series of biochemical events resulting in increases in oxygen consumption, cell motility, pinocytotic activity, and, under specific conditions, the secretion of lysosomal enzymes and the production of superoxide anion $\left(\mathrm{O}_{2}^{-}\right)[3,35]$. Three of the early events associated with chemotactic factor-induced stimulus response coupling in the neutrophil include changes in ion fluxes across the cell membrane with a depolarization of the resting transmembrane potential $[20,31]$, an increase in intracellular calcium concentration $[3,37]$, and the S-adenosyl-methionine (Ado Met)mediated methylation of specific phospholipids and proteins $[16,27]$. Studies in several laboratories have shown that under normal physiologic conditions the depolarization of the resting transmembrane potential, increase in intracellular calcium, and methylation of specific protein and phospholipid substrates precede and appear to be required for full expression of chemotactic factorinduced polymorphonuclear (PMN) biologic responses $[9,10,16,21,25,27,28,30,42]$. Although similar changes have been observed after stimulation of other inflamma- tory cells $[1,18,22,23,43]$, the role of methylation reactions in regulating stimulus-induced cell membrane depolarization, changes in intracellular calcium, and PMN functional responses is not clearly defined.

To define better the interaction between Ado Metmediated methylation reactions and the early biochemical events associated with chemotactic factor stimulusresponse coupling and PMN functional responses, we investigated the effects of 3-deaza-adenosine (3-DZA), a known inhibitor of methylation reactions in phagocytic and other cells $[6,16,22,43]$, on formyl-methionyl-leucylphenylalanine (FMLP)-induced cell membrane depolarization, changes in intracellular calcium levels, and three functional responses: $\mathrm{O}_{2}^{-}$production, lysosomal enzyme release, and stimulus-induced fluid phase pinocytosis.

Received September 12, 1988; accepted September 26, 1988.

Reprint requests: J.C. Fantone, Department of Pathology, University of Michigan Medical School, 1301 Catherine Rd., Ann Arbor, MI 48109 . 


\section{MATERIALS AND METHODS Cells}

Human peripheral blood neutrophils were obtained from normal volunteers and purified by Ficoll-Hypaque gradient centrifugation followed by ammonium chloride lysis of contaminating erythrocytes [13]. Using this technique, cell preparations routinely contained greater than $90 \%$ neutrophils with cell viability greater than $90 \%$ as determined by trypan blue exclusion.

\section{Reagents}

All reagents were purchased from Sigma Chemical Co., (St. Louis) unless otherwise noted. 3-Deaza-adenosine was purchased from Southern Research Corp. (Birmingham, AL) and was made fresh each day. Stock solutions of FMLP and phorbol myristate acetate (PMA) were prepared at a concentration of $10^{-2} \mathrm{M}$ and $1 \mathrm{mg} / \mathrm{ml}$ in dimethylsulfoxide, respectively. The fluorescent probe di-S- $\mathrm{C}_{3}-(5)$ (Molecular Probes, Inc., Junction City, OR) was prepared as a stock solution of $2 \times 10^{-3}$ $M$ in ethanol. Quin-2 AM was purchased from Lancaster Synthesis, Ltd, England. 15-(S)-15-methyl $\mathrm{PGE}_{1}$ was kindly provided by Dr. John Pike (Upjohn Co., Kalamazoo, MI).

\section{Superoxide Assay}

Superoxide anion production by human neutrophils was determined by measuring the superoxide dismutaseinhibitable reduction of ferricytochrome $c$ to ferrocytochrome $c$ at $550 \mathrm{~nm}$ [5]. Briefly, human neutrophils suspended at a concentration between 1 and $5 \times 10^{6}$ cells/ml in Hanks' balanced salt solution (HBSS), pH 7.4, containing $0.1 \mathrm{mM}$ ferricytochrome c were preincubated at $37^{\circ} \mathrm{C}$ for $10 \mathrm{~min}$ in the presence or absence of 3-deaza-adenosine. The reactions were initiated by the addition of the specific stimulus (i.e., FMLP, PMA) in a final volume of $0.7 \mathrm{ml}$ and incubated at $37^{\circ} \mathrm{C}$ for $10 \mathrm{~min}$. The reactions were terminated by the addition of $25 \mu \mathrm{l}$ of superoxide dismutase $(1 \mathrm{mg} / \mathrm{ml})$ and $275 \mu$ l of HBSS. In those reactions in which FMLP was the stimulus, the cells were also treated with cytochalasin B $(5 \mu \mathrm{g} / \mathrm{ml})$ after preincubation with 3-deaza-adenosine but prior to addition of FMLP. The quantity of $\mathrm{O}_{2}^{-}$was calculated from the difference of absorbance between samples of cells that receive superoxide dismutase prior to activation by stimulus and those receiving superoxide dismutase after stimulation. The difference was divided by the extinction coefficient $\left(21.1 \mathrm{mM}^{-1} \mathrm{~cm}^{-1}\right)$ for the change between ferricytochrome $c$ and ferricytochrome $c$ to determine nmol of $\mathrm{O}_{2}^{-}$produced by a given quantity of cells. The data are expressed as mean values in triplicate samples \pm standard error of the mean.

\section{Measurement of Cell Transmembrane Potential}

Membrane potential changes were measured as previously described [11]. Briefly, neutrophils $\left(2 \times 10^{6}\right.$ cells $/ \mathrm{ml}$ ) were exposed to $2 \times 10^{-6} \mathrm{M}$ di-S-C $\mathrm{C}_{3}-(5)$ at $37^{\circ} \mathrm{C}$ until a baseline fluorescence intensity was obtained as measured using a Varian SF330 spectrophotometer, usually in less than $3 \mathrm{~min}$. The cells were stimulated with various concentrations of FMLP or PMA, and the maximum change in fluorescence (excitation at $622 \mathrm{~nm}$, emission at $655 \mathrm{~nm}$, and band widths of $10 \mathrm{~nm}$ ) was determined. The resting membrane potential was determined using the "null point" method [31]. Membrane potential changes were expressed as maximum change in fluorescence $(\Delta F)$.

\section{Preparation of Subcellular Membrane Particles and NADPH Oxidase Assay}

NADPH oxidase activity was determined in the $27,000 \mathrm{~g}$ fraction obtained from sonicated neutrophils as previously described [25]. Briefly, human neutrophils $\left(1 \times 10^{7} \mathrm{cells} / \mathrm{ml}\right)$ were equilibrated in $\mathrm{HBSS}$ at $37^{\circ} \mathrm{C} \times$ $10 \mathrm{~min}$, followed by stimulation with PMA (100 ng/M) for $10 \mathrm{~min}$ at $37^{\circ} \mathrm{C}$. The cells were washed once, sonicated $\left(30 \mathrm{~W}\right.$ for $\left.10 \mathrm{sec} \times 3,4^{\circ} \mathrm{C}\right)$, and subjected to low-speed $(600 \mathrm{~g})$ centrifugation to remove intact cells and nuclei. The supernatant was centrifuged at $27,000 \mathrm{~g}$ for $20 \mathrm{~min}\left(4^{\circ} \mathrm{C}\right)$, and the resulting pellet was obtained and designated as subcellular particles. Subcellular particles from PMA-treated cells were treated with 3-DZA $\left(5 \times 10^{-4} \mathrm{M}\right)$ for $10 \mathrm{~min}$ at room temperature prior to assay for NADPH oxidase. $50 \mu \mathrm{l}$ of each preparation was assayed for NADPH-dependent and SOD-sensitive $\mathrm{O}_{2}^{-}$production for $15 \mathrm{~min}$ at room temperature and compared to control (non-3-DZA treated) subcellular particles. Particles from non-PMA-stimulated cells routinely produce less than $2 \mathrm{nmol}$ of $\mathrm{O}_{2}^{-}$per $\mathrm{mg}$ protein, while particles from PMA-stimulated cells generate between 50 and $100 \mathrm{nmol}$ of $\mathrm{O}_{2}^{-}$per $\mathrm{mg}$ protein depending upon the cell preparation.

\section{Cyclic AMP Assay}

One milliliter of cells $\left(10^{7}\right.$ cells $\left./ \mathrm{ml}\right)$ was incubated in the presence or absence of 3-DZA for $10 \mathrm{~min}$ at $37^{\circ} \mathrm{C}$. The reaction was stopped by placing the cells in a boiling water bath. Cyclic AMP levels were then determined by radioimmunoassay (New England Nuclear, Boston).

\section{Measurement of Intracellular Calcium Levels}

Measurement of free intracellular calcium was determined using the calcium chelator Quin-2 [41]. Human neutrophils $\left(10^{8}\right.$ cells $/ \mathrm{ml}$ in HBSS $)$ were incubated in the presence of the nonpolar ester derivative of Quin-2 (Quin-2/AM $100 \mu \mathrm{M}$ ), which is hydrolyzed intracellu- 
larly, trapping in the cytoplasm the calcium-sensitive fluorescent probe Quin-2. After a 10-min incubation at $37^{\circ} \mathrm{C}$ the cells were diluted tenfold and incubated an additional $40 \mathrm{~min}$, washed once, and resuspended in HBSS $\left(10^{7}\right.$ cells $\left./ \mathrm{ml}\right)$. Fluorescent measurements are determined using a Varian SF-330 model spectrofluorometer in a temperature-controlled cuvette $\left(37^{\circ} \mathrm{C}\right)$. Excitation and emission wavelengths for measuring Quin-2 fluorescence were $339 \mathrm{~nm}$ and $492 \mathrm{~nm}$, respectively, with slit widths of $3 \mathrm{~nm}$. Cells were preincubated in the presence or absence of 3-DZA for $10 \mathrm{~min}$ within the cuvette and subsequently stimulated with FMLP.

\section{Fluid Pinocytosis Assay}

Stimulated fluid pinocytosis by human neutrophils was determined by measuring the uptake of extracellular fluorescein-labeled dextran (mw 70,000) using a flow cytometer, as previously described $[8,28]$. Briefly, human neutrophils suspended at a concentration of $1-3 \times$ $10^{6} \mathrm{cells} / \mathrm{ml}$ in HBSS containing $1 \mathrm{mM}$ EDTA and $1 \%$ bovine serum albumin (BSA), $\mathrm{pH} 7.4$, were preincubated at $37^{\circ} \mathrm{C}$ for $10 \mathrm{~min}$ in the presence or absence of $5 \times$ $10^{-4} \mathrm{M}$ 3-DZA. Cell suspensions were stimulated with various concentrations of FMLP or PMA in the presence of $1 \mathrm{mg} / \mathrm{ml}$ FITC-Dextran in the presence or absence of $5 \mu \mathrm{g} / \mathrm{ml}$ cytochalasin B for periods of $10 \mathrm{~min}$ for dose-response studies and 0-30 min for kinetic studies. The assay was terminated by the addition of equal volumes of $4 \%$ paraformaldehyde in PBS. After a 10-min fixation period, cell suspensions were washed with PBS and analyzed for FITC-dextran uptake on a Coulter EPICS V flow cytometer using a 5-W argon laser. Flow cytometric measurements of FITC-dextran uptake over a 256-channel three-decade log scale were obtained on 10,000 neutrophils, defined by light-scatter properties, using the $488-\mathrm{nm}$ laser line at a $500-\mathrm{mW}$ output and $515 \mathrm{~nm}$ long-pass absorbance and interference filters. The results of the fluid pinocytosis assay were expressed as the mean channel number of the uptake of the FITC-dextran by the neutrophils in each sample.

\section{RESULTS}

3-DZA inhibited $\mathrm{f}$ Met-Leu-Phe-induced $\mathrm{O}_{2}^{-}$production by human neutrophils (Fig. 1). When human neutrophils were incubated with 3-DZA $\left(5 \times 10^{-4} \mathrm{M}\right)$ for $10 \mathrm{~min}$ at $37^{\circ} \mathrm{C}$ there was an approximate $60 \%$ inhibition of maximal FMLP-induced $\mathrm{O}_{2}^{-}$production. Increasing concentrations of FMLP only partially overcome the inhibitory effects of 3-DZA. The inhibition of FMLP-induced $\mathrm{O}_{2}^{-}$production by 3-DZA was dose dependent (Fig. 2) over a range of $5 \times 10^{-5}$ to $5 \times 10^{-4} \mathrm{M}$. This

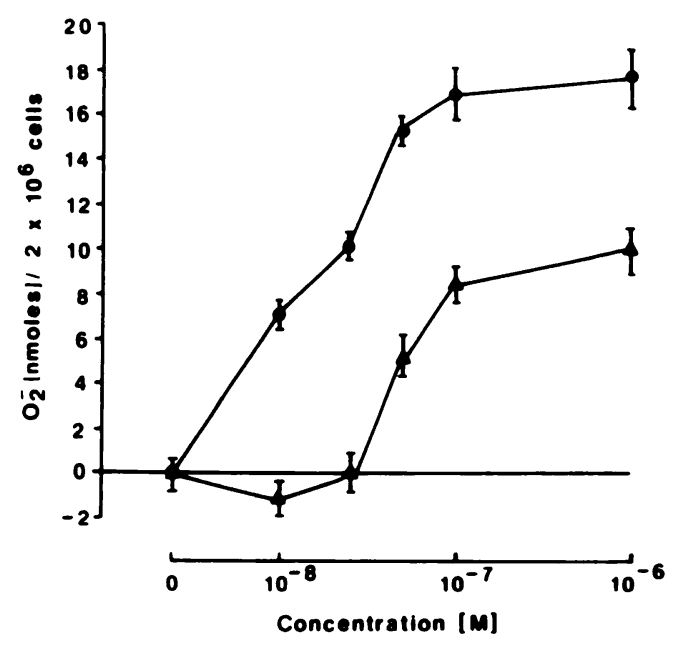

Fig. 1. Effect of 3-DZA on $f$ Met-Leu-Phe $\mathrm{O}_{2}^{-}$production. PMNs were preincubated with 3-DZA $\left(5 \times 10^{-4} \mathrm{M}\right)$ for $10 \mathrm{~min}$ at $37^{\circ} \mathrm{C}$ prior to stimulation with varying concentrations of FMLP $\left(37^{\circ} \mathrm{C}\right.$ for $5 \mathrm{~min}$ ). The amount of $\mathrm{O}_{2}^{-}$was determined and normalized per $2 \times 10^{\circ}$ cells. $\bullet=$ control (FMLP alone); $\Delta=3-D Z A+$ FMLP.

is a concentration range previously shown to inhibit Ado Met-dependent phospholipid and protein methylation reactions in neutrophils $[2,15]$. Increasing concentrations of 3-DZA above $5 \times 10^{-4}$ to $10^{-3} \mathrm{M}$ did not consistently increase the inhibition of $\mathrm{O}_{2}^{-}$production. The inhibition of FMLP-induced $\mathrm{O}_{2}^{-}$by 3-DZA was reversible. Neutrophils preincubated with 3-DZA $\left(5 \times 10^{-4} \mathrm{M}\right)$ at $37^{\circ} \mathrm{C}$ for $10 \mathrm{~min}$ and subsequently washed in HBSS and equilibrated at $37^{\circ} \mathrm{C}$ (for $10 \mathrm{~min}$ ) showed a normal $\mathrm{O}_{2}^{-}$ response to stimulation with FMLP (data not shown). In contrast, incubation of 3-DZA-treated PMNs with S-adenosyl-methione (up to $10^{-3} \mathrm{M}$ ) prior to stimulation with FMLP did not significantly reverse the inhibition of $\mathrm{O}_{2}^{-}$ production (data not shown). This may reflect the rapid decarboxylation of S-adenosyl-methionine that occurs in cells [29] or the lack of significant SAM uptake by cells to reverse 3-DZA inhibition.

The stimulus specificity for the inhibitory effect of 3-DZA on neutrophil $\mathrm{O}_{2}^{-}$production was examined. Pretreatment of neutrophils with 3-DZA at concentrations up to $10^{-3} \mathrm{M}$ did not significantly alter the production of $\mathrm{O}_{2}^{-}$by PMA-stimulated neutrophils over a broad range of concentrations (Fig. 3). Additional studies using membrane particle fractions derived from PMA-stimulated cells failed to demonstrate a direct inhibitory effect of 3-DZA on NADPH oxidase activity (data not shown). These data indicate that the ability of 3-DZA to inhibit FMLP-induced $\mathrm{O}_{2}^{-}$production is not the result of direct inhibition of the cell membraneassociated NADPH oxidase system.

In additional studies treatment of PMNs with 3-DZA 


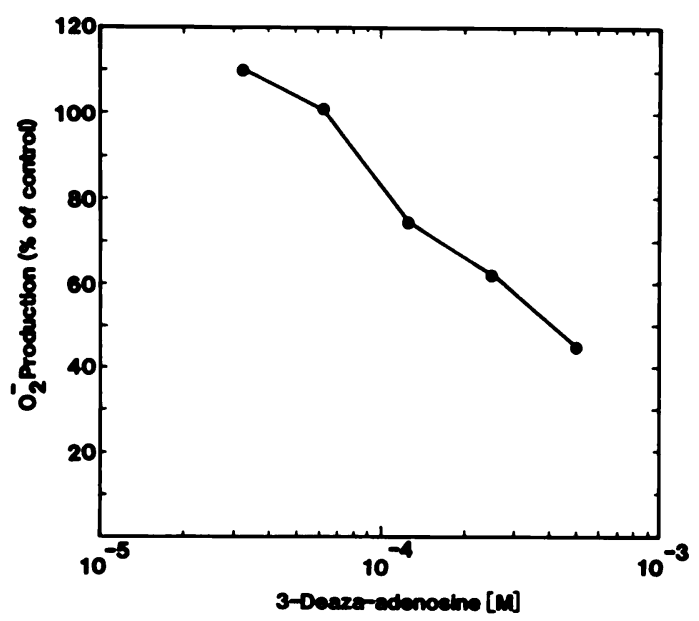

Fig. 2. Effect of 3-DZA on $f$ Met-Leu-Pho-induced $\mathrm{O}_{2}^{-}$production. PMNs were preincubated with varying concentrations 3-DZA for $10 \mathrm{~min}$ at $37^{\circ} \mathrm{C}$ prior to stimulation with FMLP $\left(10^{-7} \mathrm{M}\right), 37^{\circ} \mathrm{C}$ for $5 \mathrm{~min}$. The amount of $\mathrm{O}_{2}^{-}$produced was determined (see "Materials and Methods") and expressed as \% of control (no 3-DZA).

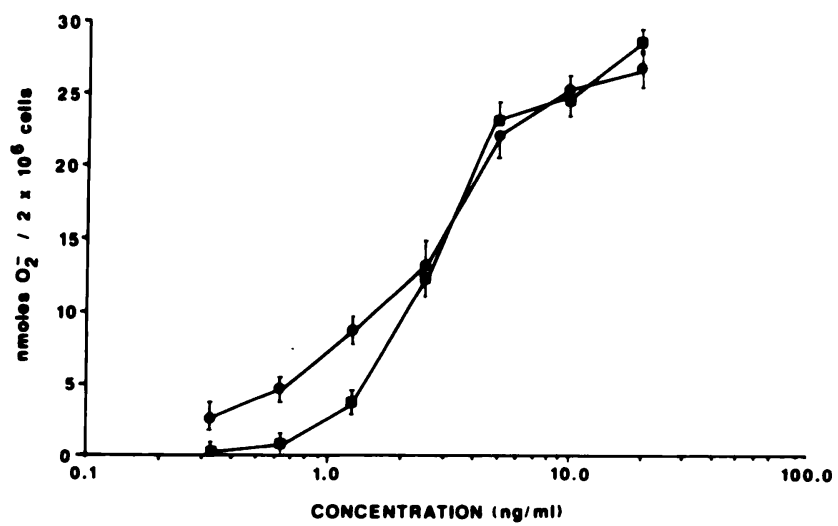

Fig. 3. Effect of 3-DZA on PMA-Induced $\mathrm{O}_{2}^{-}$production. PMNs were preincubated with 3-DZA $\left(5 \times 10^{-4} \mathrm{M}\right)$ for $10 \mathrm{~min}$ at $37^{\circ} \mathrm{C}$ prior to stimulation with varying concentrations of PMA $\left(37^{\circ} \mathrm{C} \times\right.$ $5 \mathrm{~min}$ ). The amount of $\mathrm{O}_{2}^{-}$was determined and normalized per $2 \times 10^{6}$ cells. $\bullet=$ control (PMA alone); $\square=3-D Z A+$ PMA.

only partially altered the ability of FMLP to induce lysosomal enzyme release. Pretreatment of PMNs with 3-DZA $\left(5 \times 10^{-4} \mathrm{M}\right.$ for $10 \mathrm{~min}$ at $\left.37^{\circ} \mathrm{C}\right)$ resulted in a $17.8 \pm 5.7 \%(n=7)$ inhibition of $N$-acetyl-glucosaminidase secretion compared to a $52.8 \pm 4.7 \%(n=8)$ inhibition of $\mathrm{O}_{2}^{-}$production. Increasing the concentration of 3-DZA did not significantly enhance its inhibitory effect on FMLP-induced degranulation.

Pretreatment of PMN with 3-DZA $\left(10^{-4} \mathrm{M} \times 10\right.$ min, $37^{\circ} \mathrm{C}$ ) inhibited FMLP-stimulated fluid pinocytosis (Fig. 4) by approximately $50 \%$ (range $30-80 \%$ for eight experiments). A 26-channel difference in the log scale represents a doubling of fluorescence intensity. The

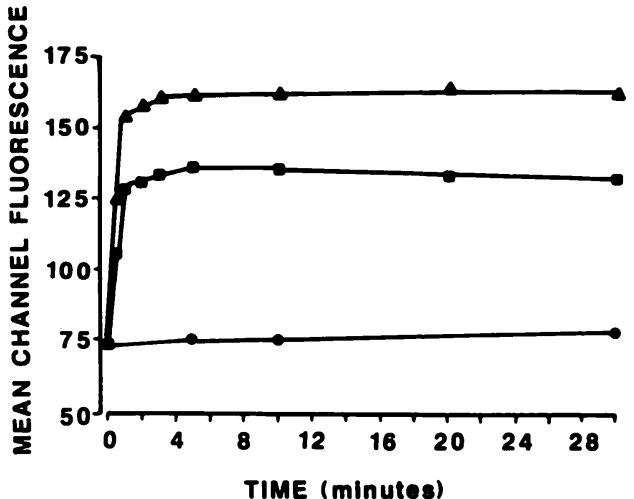

Fig. 4. Effect of 3-DZA on FMLP-atimulated fiuld pinocytosis. Flow cytometric quantitation of the maximal uptake of the extracellular fluid marker FITC-Dextran $(1.0 \mathrm{mg} / \mathrm{ml})$ of 10,000 PMNs, expressed as the mean channel fluorescence. $\triangle=$ FMLP $\left(10^{-7} \mathrm{M}\right) ; \boldsymbol{\square}=$ FMLP $+5 \times 10^{-4} \mathrm{M}$ 3-DZA; $\bullet=$ untreated cells.

inhibitory effect of 3-DZA on FMLP-stimulated activity was not overcome by increasing the concentration of stimulus, and the $\mathrm{ED}_{50}$ in the presence and absence of 3-deaza-adenosine (between 3 and $8 \times 10^{-9} \mathrm{M}$ ) was not significantly altered. In contrast, 3-DZA at $5 \times 10^{-4} \mathrm{M}$ had no inhibitory effect on PMA-stimulated neutrophil fluid pinocytosis (Fig. 5). Dose-response studies with $5 \times 10^{-4} \mathrm{M}$ 3-DZA and 10-min incubations showed no differences with PMA over a $10^{-10}-10^{-6} \mathrm{M}$ range. Kinetic analysis of the stimulated fluid pinocytosis over 30 min showed minimal inhibitory effect of 3-DZA on the initial rate of either PMA- or FMLP-stimulated fluid uptake. The presence of $5 \mu \mathrm{g} / \mathrm{ml}$ cytochalasin B (cyto B) was not necessary for either the occurrence of stimulated fluid pinocytosis or the detection of the inhibitory effect of 3-DZA on the FMLP stimulation of this neutrophil response. Interestingly, cyto $\mathrm{B}$, independent of 3-DZA, had a paradoxical effect on stimulated fluid pinocytosis, causing an augmentation of the response to FMLP and a diminution of the stimulatory effect of PMA. The nature and significance of this paradoxical cyto B effect between the two PMN stimuli is unknown and is currently under investigation.

In an effort to define more clearly the mechanism by which 3-DZA modulates PMN activation, we investigated the effects of this agent on FMLP-induced depolarization of the resting cell membrane potential. In three separate experiments, pretreatment of neutrophils with 3-DZA at concentrations up to $5 \times 10^{-4} \mathrm{M}\left(37^{\circ} \mathrm{C}\right.$ for 10 min) did not significantly alter the FMLP-induced changes in fluorescence of di-S- $\mathrm{C}_{3}$-(5)-labeled cells (Table 1). Neither the initial rate nor the maximum 


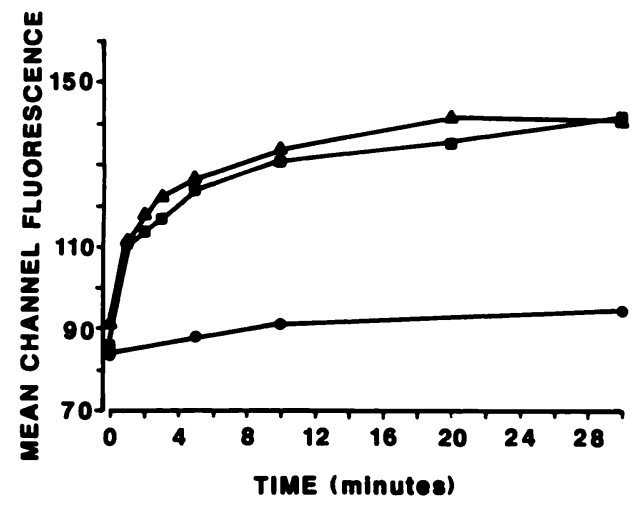

Fig. 5. Effect of 3-DZA on PMA-stimulated filuid pinocytosis. Flow cytometric quantitation of the maximal uptake of the extracellular filuid marker FTTC-Dextran $(1.0 \mathrm{mg} / \mathrm{ml})$ of 10,000 PMNs. $\triangle$ = PMA (10-7 M); $\square$ = PMA + 3-DZA (5 × 10-4 M); $\bullet=$ untreated cells.

increase in FMLP-induced fluorescence was changed. These studies indicate a 3-DZA-induced dissociation of the FMLP-induced changes in transmembrane potential from the production of superoxide anion, lysosomal degranulation, and stimulus-induced fluid phase pinocytosis in human PMNs.

Since adenosine analogs have been shown in several cell types to activate adenylate cyclase, thus increasing intracellular CAMP, and since agonists of adenylate cyclase (as well as dibuturyl cAMP) have been shown to inhibit PMN functional responses to chemotactic stimuli [Reviewed, 10], we determined the ability of 3-DZA to alter PMN intracellular cAMP levels. Pretreatment of PMNs with 3-DZA $\left(5 \times 10^{-4} \mathrm{M}\right)$ did not significantly alter intracellular cAMP levels (Table 2). This is compared to the $71.9 \%$ increase in PMN cAMP levels observed with 15-(S)-15-methyl prostaglandin $E_{1}\left(P_{1} E_{1}\right)$ (a stable analog of $P G E_{1}$ ). These data suggest that 3-DZA inhibition of FMLP-induced PMN functional responses is not mediated by increased intracellular cAMP levels.

A possible mechanism by which 3-DZA functions to inhibit PMN responses may be due to the modulation of stimulus-induced changes in intracellular calcium, especially since 3-DZA inhibits FMLP-stimulated responses and not PMA-induced responses. Chemotactic factor stimulation of PMNs is associated with a rise in free intracellular calcium levels that precedes the initiation of $\mathrm{O}_{2}^{-}$generation, degranulation, and arachidonic acid release [3,9,19-21]. However, preincubation of PMNs with 3-DZA did not significantly alter the ability of FMLP $\left(10^{-6} \mathrm{M}\right)$ to stimulate an increase in intracellular
TABLE 1. Effect of 3-DZA on $f$ Mot-Leu-Phe-Induced Changes in Fluorescence of diS-C $\mathrm{C}_{3}-(5)-$ Treated Human Neutrophils" $^{\circ}$

\begin{tabular}{lcccc}
\hline & $\mathrm{n}$ & $\Delta \mathrm{F}$ & \% change & $P$ value \\
\hline f Met-Leu-Phe $\left(10^{-6} \mathrm{M}\right)$ & 3 & $43.4 \pm 1.8$ & - & - \\
f Met-Leu-Phe $+3-\mathrm{DZA}$ & 3 & $43.6 \pm 2.6$ & +0.5 & $\mathrm{NS}$ \\
\hline
\end{tabular}

apMNs were equilibrated with diS- $\mathrm{C}_{3}-(5)$ prior to treatment with 3-DZA $\left(5 \times 10^{-4} \mathrm{M}\right)\left(37^{\circ} \mathrm{C}\right.$ for $\left.10 \mathrm{~min}\right)$. Cells were stimulated with $f$ Met-Leu-Phe, and the maximum change in fluorescent intensity $(\Delta F)$ was determined. $\Delta F$ Values represent means \pm S.E.

TABLE 2. Effect of 3-Deaza-Adenosine on PMN Intracellular CAMP Lovels"

\begin{tabular}{lccc}
\hline & \multicolumn{3}{c}{ cAMP levels picomoles $/ 4 \times 10^{6}$ cells } \\
\cline { 2 - 4 } Treatment & $\overline{\mathrm{x}} \pm \mathrm{SEM}$ & \% increase & $P$ value \\
\hline 0 & $12.8 \pm 0.7$ & - & - \\
$3-\mathrm{DZA}\left(10^{-3} \mathrm{M}\right)$ & $12.3 \pm 0.7$ & -3.9 & $\mathrm{NS}$ \\
$3-\mathrm{DZA}\left(5 \times 10^{-4} \mathrm{M}\right)$ & $12.4 \pm 0.3$ & -3.2 & $\mathrm{NS}$ \\
15-methyl-PGE $1(15 \mu \mathrm{M})$ & $22.0 \pm 1.4$ & 71.9 & .003 \\
\hline
\end{tabular}

${ }^{\text {a }} \mathrm{PMNs}$ were preincubated with 3-DZA and 15-methyl-PGE 1 for 10 min at $37^{\circ} \mathrm{C}$ prior to measurement of intracellular cAMP levels by radioimmunoassay (see "Materials and Methods").

calcium levels as monitored by changes in cellassociated Quin-2 fluorescence (data not shown). Neither the initial stimulus-induced rate of change nor maximum fluorescence intensity was consistently altered by 3-DZA treatment of the cells compared to controls. This contrasts with the marked inhibition of FMLPinduced changes in Quin-2 fluorescence observed with the calcium chelator trimethoxy-benzoic-acid-8-(diethyl amino)-ocytyl ester (TMB-8). Similar results were also observed in experiments in which INDO-1 was used as a probe of intracellular calcium levels.

\section{DISCUSSION}

S-adenosyl methionine (Ado Met)-mediated methylation reactions have been shown to play an important role in the chemotaxis of bacteria and the activation of a variety of inflammatory cells $[16,27,30]$. Recent studies have shown that 3-DZA is an effective inhibitor of Ado Met-dependent methylation reactions in a variety of cell types including mononuclear phagocytes $[7,24]$ and polymorphonuclear leukocytes $[2,15,17,27]$. The results presented here provide support to the hypothesis that FMLP-induced methylation reactions in PMNs participate in the regulation of specific biologic responses of the cell. Although 3-DZA effectively inhibits FMLPinduced neutrophil $\mathrm{O}_{2}^{-}$production, fluid pinocytosis, and chemotaxis [14], lysosomal degranulation is effected to a lesser degree. This apparent dissociation of chemotactic factor-induced PMN functional responses is supported by studies using human monocytes in which 
inhibition of cell methylation reactions correlated with a decrease in the chemotactic response of the cells without significantly altering the ability of cells to phagocytize opsonized sheep erythrocytes $[24,38]$. Additional studies demonstrated a weak correlation of inhibition of protein carboxymethylation and phospholipid methylation in mouse peritoneal macrophages with phagocytosis [39], suggesting that methylation reactions do not play a critical role in phagocytic response of these cells.

The initiation of PMN functional responses after binding of a chemotactic stimulus such as FMLP to specific receptors on the neutrophil cell membrane is preceded by a complex series of biochemical events including changes in cation fluxes across the cell membrane resulting in depolarization of the resting cell membrane transmembrane potential, activation of specific phospholipases and increased metabolism of cell membrane phospholipids and fatty acids, changes in intracellular calcium levels, and activation of specific protein kinases [reviewed in 3,37]. Although detailed studies have been performed describing each of these phenomena, the interrelationships between the individual biochemical events have only recently begun to be unraveled. Previous studies have shown that 3-DZA does not alter FMLP binding to the formyl peptide receptor on phagocytic cells $[15,38]$. Our studies extend these observations and indicate that treatment of PMNs with 3-DZA at concentrations previously shown to inhibit methyltransferase reactions $[2,15]$ does not block FMLPinduced depolarization of the cell membrane. This is in contrast to the effect of adenylate cyclase agonists that significantly block FMLP-induced changes in transmembrane potential [12]. Previous reports have shown that 3-DZA will inhibit FMLP-induced calcium influx and release of arachidonic acid from PMN phospholipids $[2,15]$, suggesting that neither the influx of calcium ions into the cell nor the release of arachidonic acid and its subsequent metabolism to biologically active compounds (e.g., $\mathrm{LTB}_{4}$ ) is a strict requirement for stimulus-induced changes in resting membrane potential. These observations are consistent with studies that show that FMLPinduced changes in transmembrane potential are independent of extracellular calcium concentration [20,31] and support the hypothesis that chemotactic factorinduced depolarization of the PMN cell membrane is an early event in stimulus response coupling of the cell $[9,21,40,42]$ and either precedes or is independent of an influx of calcium and the generation of arachidonic acid.

A number of studies have suggested that stimulusinduced calcium influx and the generation of arachidonic acid and formation of its metabolic products are critical for the initiation of a variety of functional responses in the neutrophil. However, the observation that 3-DZA has a minimal inhibitory effect on FMLP-induced lysosomal enzyme release [35] at concentrations that markedly blocked $\mathrm{O}_{2}^{-}$production, chemotaxis [15], fluid pinocytosis, calcium influx [2], and arachidonic acid release [2] indicates that the PMN degranulation response does not show the same degree of sensitivity to the regulatory mechanisms that modulate other functional responses of the cell. This is supported by studies that have shown that chemotactic factor-induced degranulation is only partially inhibited in the absence of extracellular calcium $[32,36]$. However, in the absence of extracellular calcium, minimal arachidonic acid is released, and $\mathrm{O}_{2}^{-}$ production is significantly attenuated upon stimulation of neutrophils with FMLP [33]. Since chemotactic factorinduced cell orientation, chemotaxis, and fluid phase pinocytosis are relatively insensitive to changes in extracellular calcium concentrations $[4,14,22]$, yet are significantly inhibited by 3-DZA, the data suggest that Ado Met methylation reactions do not modulate PMN functional responses solely by regulating calcium influx into the cell.

Data from many laboratories support the hypothesis that stimulus-induced changes in intracellular calcium play a significant role in the induction of functional responses of a variety of inflammatory cells. Studies by Hirata and others suggest that stimulus-induced increases in phospholipid methylation play an important role in mediating increases in intracellular calcium levels $[2,17]$. However, additional studies have failed to support this hypothesis [24]. Recently, stimulus-induced increases in phosphoinositide metabolism has been proposed as an essential metabolic pathway for the transduction of chemotactic signals in PMNs. Specifically, inositol 1,4,5 triphosphate and diacylglycerol have been suggested to function as intracellular second messengers responsible for mobilizing calcium from intracellular stores and activating protein kinase $\mathrm{C}$, respectively [reviewed in 3,35]. Moore et al. [26] using rat basophil leukemia cells, mast cells, and mouse thymocytes showed a close correlation between increased PI metabolism, stimulus-induced changes in intracellular calcium, and functional responses with only minimal changes in phospholipid methylation. Our data support these observations since 3-DZA failed to significantly alter the initial FMLP-induced rise in intracellular calcium as monitored by Quin-2 fluorescence. In human PMNs the initial changes in intracellular calcium induced by FMLP are predominantly the result of the release of calcium from intracellular stores [19,34]. Extracellular calcium influx contributes to a lesser degree to the initial rise in intracellular calcium. However, extracellular calcium plays an important role in sustaining elevated intracellular calcium levels following stimulation. In these studies, a consistent inhibition by 3-DZA of Quin-2 fluorescence (as a measure of intracellular calcium 
levels) following the initial peak response was not observed. This observation would suggest that FMLPinduced calcium influx was not significantly altered by treatment of PMN with 3-DZA. The apparent discrepancy between these observations and previous studies indicating an inhibition of calcium influx by 3-DZA [2] may be the result of additional treatment of cells with $1 \mu \mathrm{M}$ homocysteine thiolactone and a longer incubation of $30 \mathrm{~min}$ in those studies. In addition, comparison of inhibition dose-response curves for 3-DZA shows a weak correlation between inhibition of FMLP-stimulated calcium influx and cell functional responses (chemotaxis and arachidonic acid release). Thus, it appears that in human PMNs Ado Met methylation reactions may not play a critical role in regulating the release of intracellular calcium, and their role in modulating FMLPinduced calcium influx requires further study.

The differential effect of 3-DZA on FMLP- and PMA-induced fluid pinocytosis and $\mathrm{O}_{2}^{-}$production are consistent with their distinct mechanisms of PMN activation. Furthermore, the differing degrees of inhibition by 3-DZA of FMLP-induced fluid pinocytosis and degranulation further extend previous observations $[7,8]$ that pinocytosis and enzyme release are separate and distinct PMN responses. These results suggest that the effect of 3-DZA is more specific than simply causing a generalized membrane perturbation or paralysis. If the effect of 3-DZA were simply to block membrane fusion, one would expect to see a similar degree of inhibition of endocytosis and degranulation along with an alteration of the kinetics of these responses in the presence of the drug.

In summary, the data do not support the hypothesis that the primary mechanism by which 3-DZA inhibits PMN functional responses is by blocking Ado Metmediated methylation reactions that regulate intracellular calcium concentrations. However, the data do suggest that Ado Met-mediated methylation reactions may be important in the generation of additional intracellular signals that participate in the initiation of specific cell functional responses. One potential role for Ado Metmethylation reactions in PMN stimulus response coupling is in the synthesis of phosphatidylcholine from phosphatidylethanolamine and the subsequent generation of arachidonic acid via phospholipase $A_{2}$-dependent pathways. Treatment of PMNs with 3-DZA inhibits chemotactic factor-induced arachidonic acid release. However, studies in rat basophil leukocyte cells [26] indicate minimal increase in the amounts of methylated phospholipids up to $10 \mathrm{~min}$ after stimulation despite significant increases in intracellular calcium and both histamine and arachidonic acid release. Alternatively, 3-DZA may function to block protein kinase $C$ activation by either direct or indirect mechanisms. 3-DZA inhibi- tion of diacylglycerol or arachidonic acid generation could result in inhibition of stimulus-dependent protein kinase $\mathrm{C}$ activity and would be consistent with a relative lack of effect of 3-DZA on f-Met-Leu-Phe-induced changes in intracellular calcium and transmembrane potential change, as well as phorbol ester-dependent cell responses.

Thus, it appears that ligand-receptor activation of Ado Met-dependent methylation reactions play a significant regulatory role in chemotactic factor-stimulated functional responses of phagocytic cells. However, precise definition of their mechanism of action remains to be determined.

\section{ACKNOWLEDGMENTS}

This work was supported in part by NIH grants HL-32024, HL-28737, HL-31963, CA-36646 and by grants from the American Heart Association and its Michigan affiliate (J.C.F., S.H.P.). Part of the work was done during the tenure of an Established Investigatorship of the American Heart Association (S.H.P.).

\section{REFERENCES}

1. Barber, J.R., and Clarke, S. Inhibition of protein carboxyl methylation by S-adenosyl-L-homocysteine in intact erythrocytes. J. Biol. Chem. 259,7115, 1984.

2. Bareis, D.L., Hirata, F., Schiffmann, E., and Axelrod, J. Phospholipid metabolism, calcium flux, and the receptormediated induction of chemotaxis in rabbit neutrophil. J. Cell Biol. 93,690, 1982.

3. Becker, E.L. Leukocyte stimulation: Receptor membrane and metabolic events. Fed. Proc. 45,2148, 1986.

4. Becker, E.L., and Showell, H.J. The effect of $\mathrm{CA}^{2+}$ and $\mathrm{MG}^{2+}$ on the chemotactic responsiveness and spontaneous motility of rabbit polymorphonuclear leukocytes). Z. Immun. Forsch. Bd. 143,466, 1972.

5. Becker, E.L., Sigman, M., and Oliver, J.M. Superoxide production induced in rabbit polymorphonuclear leukocytes by synthetic chemotactic peptides and A23187. Am. J. Pathol. 95,21, 1979.

6. Chiang, P.K., Richards, H.H., and Canton, G.L. S-adenosylL-homocysteine hydrolase: Analogues of S-adenosyl-L-homocysteine as potential inhibitors. Mol. Pharmacol. 13,939, 1977.

7. Davis, B.H. Stimulated fluid pinocytosis in neutrophils: Effects of various stimulants measured by flow cytometry. Fed. Proc. 43,388, 1984.

8. Davis, B.H., McCabe, E., and Langweiler, M. Fluid pinocytosis in FMLP stimulated human neutrophils as measured by flow cytometry. Cytometry 7,251, 1986.

9. Di Virgilio, F., Lew, P.D., Anderson T., and Pozzan, T. Plasma membrane potential modulates chemotactic peptide-stimulated free $\mathrm{Ca}^{2+}$ changes in human neutrophils. J. Biol. Chem. 262, 4574, 1987.

10. Duque, R.E., Phan, S.H., Sulavik, M.C., and Ward, P.A. Inhibition by Tosyl-L-phenylalanyl chloromethyl ketone of membrane potential changes in rat neutrophils. J. Biol. Chem. 258,8123, 1983.

11. Fantone, J.C. Mechanisms of chemotactic factor stimulation of 
polymorphonuclear leukocytes: Modulation by prostaglandins. In Inflammatory Mediators (Higgs, G.A., and Williams, T.J., Eds.) London: MacMillan, p. 127, 1985.

12. Fantone, J.C., Duque, R.E., and Phan, S.H. Prostaglandin modulation of $\mathrm{N}$-formylmethionylleucylphenylalanine-induced transmembrane potential changes in rat neutrophils. Biochim. Biophys. Acta 804,265, 1984.

13. Fantone, J.C., and Kinnes, D.A. Prostaglandin $E_{1}$ and prostaglandin $\mathrm{I}_{2}$ modulation of superoxide production by human neutrophils. BBRC 369,506, 1983.

14. Gallin, J.I., and Rosenthal, A.S. The regulatory role of divalent cations in human granulocyte chemotaxis. J. Cell Biol. 62,594, 1983.

15. Garcia-Castro, J.M., Mato, G., Vasanthakumar, W.P., Weissman, E., Schiffman, and Chiang, P.K. Paradoxical effects of adenosine on neutrophil chemotaxis. J. Biol. Chem. 258,4345, 1983.

16. Hirata, F., and Axelrod, J. Phospholipid methylation and biological signal transmission. Science 209, 1082, 1980.

17. Hirata, F., Corcoran, B.A., Venkatasubrammanian, K., Schiffman, E., and Axelford, J. Chemoattractants stimulates degradation of methylated phospholipids and release of arachidonic acid in rabbit leukocytes. Proc. Natl. Acad. Sci. U.S.A. 76,2640, 1979.

18. Horne, W.C., and Simons, E.R. Probes of transmembrane potentials in platelets: Changes in cyanine dye fluorescence in response to aggregation stimuli. Blood. 51,741, 1978.

19. Korchak, H.M., Kienne, K., Rutherford, L.E., Wilkenfeld, C., Finkelstein, M.D., and Weissmann, G. Stimulus response coupling in the human neutrophil. J. Biol. Chem. 259,4076, 1984.

20. Korchak, H.M., and Weissman, G. Changes in membrane potential of human granulocytes antecede the metabolic responses to surface stimulation. Proc. Natl. Acad. Sci. U.S.A. 75,3818, 1978.

21. Lazzari, K.G., Proto, P.J., and Simons, E.R. Simultaneous measurement of stimulus induced changes in cytoplasmic $\mathrm{Ca}^{2+}$ and in membrane potential of human neutrophils. J. Biol. Chem. $261,9710,1986$.

22. Marasco, W.A., Becker, E.L., and Oliver, J.M. The ionic basis of chemotaxis. Am. J. Pathol. 93,749, 1980.

23. Mato, J.M., and Alemany, S. What is the function of phospholipid N-methylation? Biochem. J. 213,1, 1983.

24. Medziharadsky, J.L. Regulatory role for the immune complex in modulation of phagocytosis by 3-deazaadenosine. J. Immunol. 133,946, 1984.

25. McPhail, L.C., Henson, P.M., and Johnston, R.B., Jr. Respiratory burst enzyme in human neutrophils. J. Clin. Invest. 67,710, 1981.

26. Moore, J.P, Johannsson, A., Hesketh, T.R., Smith, G.A., and Metcalfe, J.C. Calcium signals and phospholipid methylation in eukaryotic cells. Biochem. J. 221,675, 1984.

27. Niwa, Y., Sakane, T., and Taniguchi, S. Phospholipid transmethylation in the membrane of human neutrophils and lymphocytes. Arch. Biochem. Biophys. 234,7, 1984.

28. Oliver, J.M., Berlin, R.D., and Davis, B.H. Use of horseradish peroxidase and fluorescent dextrans to study fluid pinocytosis in leukocytes. Methods Enzymol. 108,336, 1984.

29. Pezzoli, C., Stramentinoli, M., Galli-Kienle, M., and Pfaff, E. Uptake and metabolism of S-adenosyl-L-methionine by isolated rat hepatocytes. Biochem. Biophys. Res. Commun. 85,1031, 1978.

30. Pike, M.C., Kredich, N.M, and Snyderman, R. Requirement of S-adenosyl-L-methionine-mediated methylation for human monocyte chemotaxis. Proc. Natl. Acad. Sci. U.S.A. 75,3928, 1978.

31. Seligmann, B.E., Gallin, E.K., Martin, D.L., Shain, W., and Gallin, J.I. Interaction of chemotactic factors with human polymorphonuclear leukocytes: Studies using a membrane potentialsensitive cyanine dye. Membr. Biochem. 52,257, 1980.

32. Showell, H.J., Naccache, P.H., Sha'Afi, R.I., and Becker, E.L. The effects of extracellular $\mathrm{K}^{+}, \mathrm{NA}^{+}$, and $\mathrm{Ca}^{++}$on lysosomal enzyme secretion from polymorphonuclear leukocytes. J. Immunol. 119,804, 1977.

33. Simchowitz, L., and Spilberg, I. Generation of superoxide radicals by human peripheral neutrophils activated by chemotactic factor. Evidence for the role of calcium. J. Lab. Clin. Med. 93,583, 1979.

34. Sklar, L.A., and Oades, Z.G. Signal transduction and ligandreceptor dynamics in the neutrophil. $\mathrm{Ca}^{2+}$ modulation and restoration. J. Biol. Chem. 260,11468, 1985.

35. Smith, R.J., Iden, S.S., and Bowman, B.J. Activation of the human neutrophil secretory process with $5(S), 12(R)$-dihydroxy6,14-cis-8,10-transeicosatetraenoic acid. Inflammation 8,365 , 1984.

36. Smolen, J.E., Korchak, H.M., and Weissman, G. The roles of extracellular and intracellular calcium in lysosomal enzyme release and superoxide anion generation by human neutrophils. Biochim. Biophys. Acta 677,512, 1981.

37. Snyderman, R., Smith, C.D., and Verghese, M.W. Model for leukocyte regulation by chemoattractant receptors: Roles of a guanine nucleotide regulatory protein and polyphosphoinositide metabolism. J. Leukocyte Biol. 40,785, 1986.

38. Snyderman, S., Pike, M.D., and Kredich, M. Role of transmethylation reactions in cellular motility and phagocytosis. Mol. Immunol. 17,209, 1980.

39. Sung, S.S.J., and Silverstein, S.C. Inhibition of macrophage phagocytosis by methylation inhibitors. Lack of correlation of protein carboxymethylation and phospholipid methylation with phagocytosis. J. Biol. Chem. 260,546, 1985.

40. Tauber, A.I., and Simons, E.R. Dissociation of human neutrophil membrane depolarization, respiratory burst stimulation and phospholipid metabolism by quinacrine. FEBS Lett. 156,161, 1983.

41. White, J.R., Naccache, P.H., Molski, P., Borgeat, R.I., and Sha'afi, R.I. Direct demonstration of increased intracellular concentration of free calcium in rabbit and human neutrophils following stimulation by chemotactic factor. Biochem. Biophys. Res. Commun. 113,44, 1983.

42. Whitin, J.C., and Chapman, C.E., Simons, E.R., Chovanier, M.E., and Cohen, H.J. Correlation between membrane potential changes and superoxide production in human granulocytes stimulated by phorbol myristate acetate. J. Biol. Chem. 255,1874, 1980.

43. Zimmerman, T.P., Wolberg, G., and Duncan, G.S. Inhibition of lymphocyte-mediated cytolysis by 3-deazaadenosine: Evidence for a methylation reaction essential to cytolysis. Proc. Natl. Acad. Sci. U.S.A. 75,6220, 1978 . . 